NASA Technical Memorandum 105605

$1 N-20$

AIAA-91-3441

86830

p. 18

\title{
Blazing the Trailway: Nuclear Electric Propulsion and its Technology Program Plans
}

Michael P. Doherty

Lewis Research Center

Cleveland, Ohio

$$
\begin{aligned}
& \text { (NASA-TM-105605) BLAZING THE TRAILWAY: } \\
& \text { NUCLEAR ELECTRIC PROPULSION AND ITS } \\
& \text { TECHNOLOGY PROGRAM PLANS (NASA) } 18 \mathrm{p} \\
& \text { CSCL } 18 L \\
& 63 /<0
\end{aligned}
$$

Prepared for the

Conference on Advanced Space Exploration Initiative Technologies cosponsored by AIAA, NASA, and OAI

Cleveland, Ohio, September 4-6, 1991

\section{N/SA}


$=-\div-$

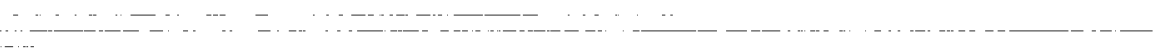


BLAZING THE TRAILWAY:

NUCLEAR ELECTRIC PROPULSION

AND ITS TECHNOLOGY PROGRAM PLANS

\author{
Michael P. Doherty \\ National Aeronautics and Space Administration \\ Lewis Research Center \\ Cleveland, Ohio 44135
}

\begin{abstract}
$+4$

This paper gives an overview of the Nuclear Electric Propulsion (NEP) technology program plans, and states characteristics of a program in NEP technology to identify and develop enabling technologies to take humans further into outer space than we have ever gone before, and to allow us greater flexibility to perform our required activity at destination. NEP offers great promise for enhancing or even enabling both piloted and unpiloted missions to the Moon and Mars, robotic science missions to the outer reaches of our solar system and beyond, and Earth-space propulsion missions. NEP Technology Program plans are driven by the need to develop the propulsion technologies required for piloted and cargo missions to the Moon and Mars, as will be required for the U.S. Space Exploration Initiative. But because interim technology developments can yield NEP technologies for robotic science and Earth-space applications, an evolutionary technology program with carefully planned programmatic milestones is being formulated. Such an evolutionary approach to the development of NEP technology may very well allow a NEP propelled vehicle to serve as a national space nuclear power/propulsion pathfinder, thus blazing the trailway to other advanced space nuclear missions.
\end{abstract}

\title{
BACKGROUND
}

In September of 1990, a joint NASA/DOE/DOD interagency steering committee for nuclear propulsion met to assess the results of two workshops held earlier that summer to present concepts for Nuclear Electric Propulsion (NEP) and Nuclear Thermal Propulsion (NTP). The steering committee recommendations formed the basis for FY 1991 Interagency plans and activities for nuclear propulsion ${ }^{1}$ :

(1) Develop a consistent basis for comparing nuclear propulsion concepts

(2) Assess facility requirements

(3) Prepare draft safety policy 
(4) Optimize missions for nuclear propulsion

(5) Develop interagency agreements

(6) Complete and approve project plans

(7) Prepare initial statements of work

(8) Initiate public acceptance planning

To address these recommendations and maintain programmatic momentum in the wake of the workshops, interagency panels were formed. These panels were focused on six critical programatic areas for nuclear propulsion:

Mission Benefits

Safety

Nuclear Thermal Propulsion (NTP) Technology

NEP Technology

Fuels and Materials Technology

Test Facilities

As such, the NEP Technology Panel found itself chartered with the responsibility to address the high priority activities pertinent to NEP technology development. The objectives and products of the NEP Technology Panel, as shown in Figure 1, included initiating the planning for a NEP Technology Program.

This paper gives an overview of these NEP Technology Program plans and states programmatic characteristics for NEP technology development.

\section{NEP MISSIONS AND TECHNOLOGIES}

The advent of the National Space Exploration Initiative (SEI), in conjunction with NASA's active robotic planetary exploration program, and a burgeoning interest in augmented near-Earth missions has led to interest in Nuclear Electric Propulsion for future missions. ${ }^{2}, 3,4,5$ These missions span a range of activity:

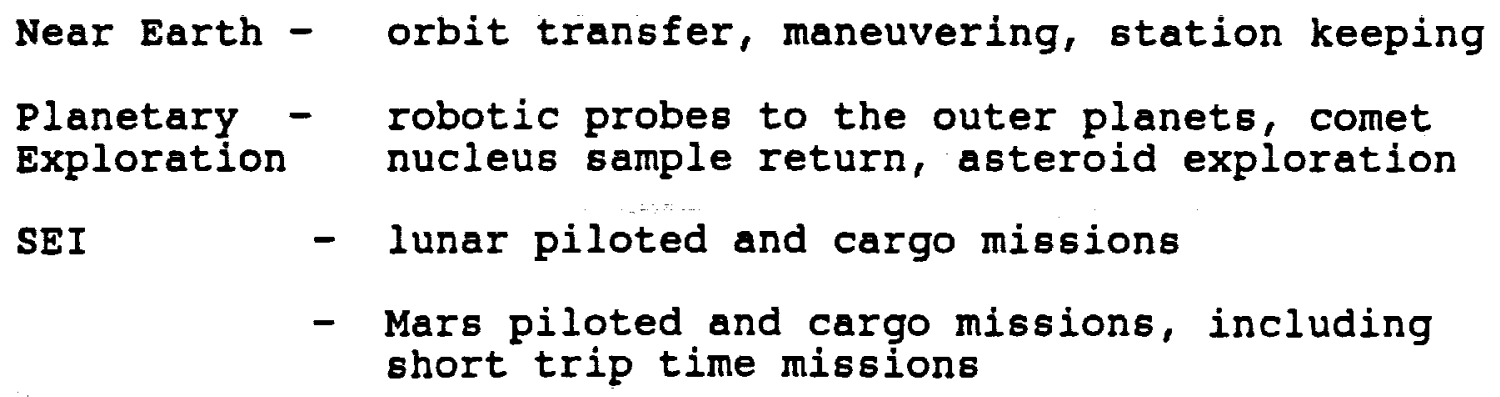


The propulsion requirements of these missions have been translated into NEP system requirements (Figure 2). As can be seen from this figure, the last three mission categories are related to SEI, while the first two are not. System requirements for each category specify high values of specific impulse, a key strength of NEP. Electric thruster on-time is characterized in terms of years, indicating the kind of durability which will be required of the propulsion system. As more demanding missions are addressed, progressively higher electrical power levels, as well as progressively lower values of power/propulsion system specific mass will be required.

NEP is a propellant-efficient type of low thrust-to-weight propulsion for space-based applications. NEP systems employ a nuclear reactor as a thermal source used to generate electricity to drive an electric thruster. A power conversion system converts the thermal energy to electrical power for subsequent use in the electric thruster (Figure 3). The low acceleration characteristic of NEP is countered by its high specific impulse, or amount of thrust per unit mass of propellant flowrate. Thus propulsion system requirements can be achieved with a propellant mass up to an order of magnitude less than that used by other propulsion systems.

NEP offers great promise for enhancing or even enabling both piloted and unpiloted missions to the Moon and Mars, robotic science missions to the outer reaches of our solar system and beyond, and Earth-space propulsion applications.

For Mars piloted missions, NEP offers benefits in trip time, low initial mass in low Earth orbit (IMLEO), decreased variation with opportunity, lengthened Earth launch windows, longer Mars stay windows, and mission aborts. A NEP-propelled vehicle having an IMLEO of just 400 metric tons (includes hab module and propellant) can provide 400-day piloted round trip times to/from Mars, performance that is quite comparable with that of high thrust systems, including NTP. Because of its variable coast arCs, NEP offers decreased variation in propellant consumption with opportunity, making the idea of designing a vehicle for multiple mission opportunities more feasible. This is a feature which ballistic propulsion options do not usually offer. NEP offers significant flexibility in Earth launch window, allowing even up to a 60-day variation in launch date for the 2014 Mars opportunity without the need for additional propellant. Also, a 90-day nominal Mars stay window can be reduced to a zero-day stay for the same 2014 Mars piloted mission without any penalty whatsoever (propellant or triptime). NEP also has abort capability for the Mars piloted mission, if needed.

For cargo missions, NEP has the potential for flight system reusability and extremely low IMLEOs.

For robotic science missions, NEP enables a Pluto Orbiter mission, having flight times on the order of ten to twelve 
years. ${ }^{7}$ NEP provides the ability to rendezvous with the major satellites of Jupiter, Neptune and Pluto versus a mere flyby using ballistic propulsion. Multiple body encounters of the Jovian system are possible with one launch using NEP; also possible are multiple main belt asteroid encounters in a single launch.

For Earth-space missions, NEP allows the transfer of large epacecraft from low-Earth-orbit to geostationary orbit (IEO to GEO), thereby reducing the size of ballistic upper stages.

Five major subsystems comprise a NEP system: reactor (including shielding), power conversion, thermal management, power management and distribution (PMAD), and electric thruster. Table 1 lists the broad trade space of NEP subsystem technologies considered applicable for future missions requiring NEP. A wide range in maturity is evident across these technologies, ranging from proof-of-concept to existing development programs. Various reactor types are identified, including liquid metal cooled, gas cooled, incore thermionic, and vapor core. Pin-type liquid metal cooled reactors are separated into SP-100 reactor technology versus more advanced, higher temperature pin-type reactors. Gascooled reactors include the NERVA Derived Reactor, particle bed, pellet bed, and cermet reactors. A large number of potential power conversion schemes have been identified, both static and dynamic. Thermal management is broken down into heat pipe, pumped loop, and liquid sheet or droplet concepts. Further distinction of heat pipe technologies has been made by material. PMAD technologies are distinguished by high power, high temperature, radiation-resistant electronics, with high efficiences and low specific masses being the goal. A range of electric thruster concepts has been identified, including a steady-state electrostatic engine, a number of steady-state and pulsed electromagnetic engines, and a pulsed electrothermal/ electromagnetic engine ${ }^{8}$.

The number of NEP systems capable of meeting the requirements of any one of the mission categories is great, with some systems having promise to meet the requirements of more than one mission. Near-Earth and planetary robotic missions might utilize a sp-100 type reactor (2.4 MWt) and thermoelectric power conversion with ion thrusters, because of the requirement for low power (10's to 100 's of kilowatts of electric power) and near term availability. If these missions require more power, it might be necessary to develop a higher efficiency, lower specific mass power conversion system such as Brayton or Potassium-Rankine. Cargo and piloted vehicle requirements might be satisfied by a reactor which makes use of the fuels, materials and reactor technologies from the SP100 program in a larger sized reactor (with dynamic power conversion). Studies have shown that relatively fast fourhundred day class Mars piloted missions can be performed utilizing a two-year-life NEP system based on SP-100 reactor technology". If reusable flight systems are required for fourhundred day class Mars piloted missions, then the development of 
completely new higher-temperature reactor technology (liquidmetal-cooled or gas-cooled) might be warranted. Rather than ion thrusters, cargo and piloted vehicles might employ magnetoplasmadynamic (MPD) thrusters, because of the potential of MPD to operate at high power levels. Vapor Core/ Magnetohydrodynamic (MHD) power concepts and pulsed electromagnetic thrusters are higher performance technologies that might be applied in more innovative system concepts.

Because the ultimate goal of the NEP Technology program is to provide the technologies for a space propulsion system for the Mars piloted mission, and there is a range of NEP missions requiring less power than that, it makes sense to plan an evolutionary program in NEP technology ${ }^{10}$. An evolutionary approach to the development of NEP technology is characterized by interim milestones which would yield the technologies for Earthspace, interplanetary robotic, and even lunar and Mars cargo missions.

Because NEP is applicable to a number of missions, and there is a host of candidate technologies, there is a need to perform a detailed systems/ subsystems trade study to determine optimum combinations of those technologies. Such a trade study would provide a reference point for the initiation of detailed technology programs. This study could also be supplemented with a conceptual design activity to provide reference system design(s) for specific mission applications. A systems/ subsystems trade study activity is vital in the early program years for NEP.

\section{NEP TECHNOLOGY PLANS}

NEP Technology Program plans are driven by the need to develop the propulsion technologies for piloted and cargo missions to the Moon and Mars, as will be required for the U.S. Space Exploration Initiative. But because interim technology developments can yield NEP technologies for robotic science and near-Earth station keeping applications, an evolutionary technology program with carefully planned programmatic milestones is being formulated. An overview of the technology project plan appears in Figure 4.

The NEP Technology Program involves the identification, development, and verification of NEP technologies including reactor, power conversion, thermal management, PMAD and thrusters over an approximately 15 year time period, beginning in 1992. The ultimate goal is Technology Readiness Level 5 (TRL-5), defined as subsystem demonstration in a relevant environment. Toward this end, the program will also include program elements for Concept Development/ Systems Engineering, Facility Development, Safety, Quality Assurance, Reliability and Environment, as well as Project Management. 


\section{Concept Development/Systems Engineering}

The Concept Development/ Systems Engineering element will be an important guiding activity to the project. It will be under this element that system requirements will be maintained, trade studies performed, test hardware designed and fabricated, and subsystem tests performed.

In addition to subsystem testing to TRI-5 of the NEP technologies required for the Mars piloted mission, two other critical milestones under this element are to be noted. The first milestone is completing a system/ subsytem trade study by FY93. This trade study involves the comparison of NEP systems (comprised of the candidate technologies) using common ground rules and assumptions, to determine the most advantageous NEP technologies to pursue in the technology program. such an activity must be performed in the early years of the program.

The second milestone is the demonstration of lightweight, megawatt-class power conversion in a relevant environment by 2000. A demonstration of a MW-class power conversion system that is lighter in weight, more efficient, and higher in power than thermoelectrics could yield the power conversion technology necessary for planetary robotic NEP missions requiring power levels between 100 and $500 \mathrm{kilowatt}$ electric (kWe), using the sp100 reactor. It could also provide the power conversion technology necessary for lunar and Mars cargo missions (which would use a larger-sized SP-100 reactor or advanced reactor). Meeting this milestone would enable NEP to enter the next higher realm of electrical space power beyond what the base SP-100 technology program offers, and it would be only at the cost of developing one subsystem technology. Follow-on subsystem testing of a larger power conversion system using the same technology or another technology could be performed in 2005, if required.

\section{NEP Technology}

The NEP Technology and Innovative Technology elements will be the heart and soul of the NEP technology program. It is within the NEP Technology element that desirable technologies identified as having high benefit/risk ratios will be developed and verified. Component level validation testing will be performed at this level. The specific component technologies to be addressed are described below.

\section{Nuclear Fuels}

NEP system requirements for high power, long life and low specific mass drive the need for high temperature, long life, stable nuclear fuel forms (Figure 5). In addition to pin-type fuel forms, coated particles and ceramic/cermet forms appear 
likely candidates to meet the requirements. Recommendations of the Fuels and Materials Technology panel will be important for guiding this nuclear fuels subelement ${ }^{11}$.

A pin-type fuel comprised of Uranium Nitride (UN) pellets enclosed in a $\mathrm{Nb}-1 \mathrm{zr}$ clad tube is currently being irradiation tested under the SP-100 program. Even so, the mission requirements for SEI space propulsion applications may dictate that a higher performance pin-type fuel is eventually required. This higher performance UN fuel could be developed by using higher temperature cladding materials, which could be screened in the early years of the program.

Coated UC-ZrC particles are employed in three gas-cooled reactor concepts, the Nerva Derived Reactor (NDR), Particle Bed Reactor (PBR) and Pellet Bed Reactor. In the early years of the program, issues associated with properties and fabrication of particle fuels are to be separately addressed under a Nuclear Thermal Propulsion technology program. This work will be closely tracked for its applicability to NEP.

Cermet fuels (Uranium Nitride or Uranium Dioxide), with appropriate coatings, are applicable to either liquid-metalcooled or gas-cooled reactors.

The early years of the NEP nuclear fuels technology program will address issues associated with material properties and

fabrication of high performance UN pin-type and Cermet fuels, until NEP systems/ subsystems trade study results clarify which fuel technology $(s)$ is best to pursue. A critical nuclear fuels technology milestone is to complete fuel element irradiation testing by 1998, to allow testing of fuel in a prototype reactor.

\section{Power Conversion}

Development of efficient, high temperature power conversion technology will be undertaken as part of the technology program. Both thermoelectric and thermionic power conversion technologies are being investigated under current technology programs - SP100 in the case of thermoelectrics and DOD programs in the case of thermionics. Stirling power conversion technology is also being investigated under an existing NASA program ${ }^{12}$. Because these power conversion technologies have applicability to kWeclass NEP system applications, progress of these technologies may very well only be tracked by the NEP program. The NEP technology program will focus on power conversion technologies having promise for megawatt-class applications by way of reduced specific mass, such as Rankine ${ }^{13}$ and Brayton dynamic power conversion and possibly in-core thermionic. Some componentlevel development activities for Rankine cycle power conversion would require a start in very early program years. Once again, the NEP systems/ subsystems trade study will be critical in defining which power conversion technologies to pursue outright, 
as well as which technologies to encourage development of for lower power NEP applications. A critical power conversion technology milestone is completion of component testing by 1998 , to enable subsystem testing in a relevant environment.

\section{Thermal Management}

Thermal management systems (radiators) are a significant portion of the mass of megawatt electric (MWe) space power systems, especially for power systems with relatively low heat rejection temperatures. As such, much work needs to be done to reduce the size and mass of these systems. Current space radiator technologies for high temperature heat rejection employing refractory metal alioys have planar specific masses on the order of 10 kilograms per square meter. To enable high performance NEP systems, radiator planar mass must be reduced to 5 kilograms per square meter or less, a goal believed achievable using carboncarbon or ceramic fiber heat pipe technology. A critical thermal management technology milestone is completion of lightweight radiator segment testing by 1997 , to support $\mathrm{MW}$-class power conversion subsystem testing in a relevant environment by 2000 .

\section{Power Management and Distribution}

Power Management and Distribution (PMAD) subsystems for NEP will require that high temperature, multimegawatt, radiation resistant power electronics be developed. Conventional power electronics are based on silicon devices. These Si devices successfully operate at temperatures up to 450 degrees $\mathrm{K}$ before suffering thermal runaway. Using conventional silicon power electronics and power components, it will be possible to provide the PMAD technology for $100 \mathrm{kWe-class}$ NEP missions by the late 1990's. But to achieve the PMAD technology required for higher power NEP missions, it will be necessary to develop power electronics with wider band gap semiconductors, capable of operating up to 600 degrees $R$. Silicon Carbide (SiC) is the best choice based on material properties and band gap, but Aluminum Galium Arsenide (AlGaAs) is also a prime candidate because of its maturity. Important PMAD technology milestones are the determination of efficiences, lifetimes, and radiation resistance of 450 degree $K$ and 600 degree $K$ power electronics technology by 1997 and 2004 respectively.

\section{Electric Thrusters}

Although there is a host of candidate electric thruster technologies, inert gas ion thrusters and magnetoplasmadynamic (MPD) thrusters are the most mature concepts. Ion demonstrates high performance and long life at low power, $1-5 \mathrm{kWe}$, and MPD thrusters have demonstrated high power capacity for short periods of time. Pulsed electromagnetic devices and electrodeless 
thrusters do not have sufficient technical maturity to be incorporated into the early high power technology demonstration programs, but feasibility and practicality demonstrations of advanced concepts are needed early in the program.

The program will concentrate on determining the performance and life limits of kWe-class and MWe-class electric thrusters (Figure 6). After scaling, performance limits, and life limits are established for a given application and power level, a downselect of thruster concepts will be made for further development under a focused technology program. Focused technology programs will be directed toward NEP robotic, cargo, and piloted vehicle applications. The major products of the focused programs will be the development of high performance, low specific mass engineering model electric thrusters and power processor breadboards. Thrusters and power processors will be integrated, and critical interfaces will be defined for thruster, power, thermal, propellant management, and instrumentation/control subsystems. Life verification tests will be undertaken in parallel with thrust subsystem electromagnetic compatibility, plume, and cluster interaction tests using the engineering model hardware. Electric thruster technology milestones include kWclass ion engine design verification by 1995 and downselect of $\mathrm{MW}$-class engine technology by 1998.

\section{Innovative Technology}

The Innovative Technology element of the program will consider candidate technologies having significant potential to impact NEP mission applications, but having unsolved technical issues too fundamental to warrant their inclusion in the baseline enabling technology program. NEP candidate technologies to be considered here are the Direct Boiling Potassium reactor and high

temperature vapor Core reactor with magnetohydrodynamic (MHD) power conversion, electrochemical power conversion schemes, liquid sheet/liguid droplet radiators, and pulsed electromagnetic and electrodeless thrusters. Under the Innovative Technology element, studies and modeling, as well as proof-of-concept activities will be conducted. Innovative technology is expected to be an on-going functional element of the program, funded at a reasonable percentage of the overall technology program.

\section{Facilities}

The technology demonstration milestones of the NEP Technology program can only be met if adequate test facilities exist. To bring the required technologies to TRL-5, there are four major facilities that are needed: a thruster performance facility, a thruster life facility, a power conversion facility and a reactor facility. The thruster performance facility would have the capacity to test thrusters under realistic space vacuum conditions for short periods of time. The thruster life facility 
would have the capacity to test MW-class thruster models for long periods of time in a realistic environment to verify thruster performance and system lifetimes. A power conversion test facility would be required to proof out component hardware for the desired space power conversion system and possibly test the full-up power conversion system in a thermal vacuum environment. But very possibly, the complete power conversion subsystem would be co-tested with the reactor in the fourth facility, the reactor test facility. It appears that there are candidates for all four facilities located within the United States, but some reasonably significant funding will be required to modify those facilities for NEP Technology program use. Facility requirements for Nuclear Propulsion are covered in more detail in a summary discussion of the Test Facilities panel".

Safety, Quality Assurance, Reliability and Environment

An element in Safety, Quality Assurance, Reliability and Environment has been established as a important part of the program. In light of overall programmatic safety policy recommendations ${ }^{3}$, specific safety requirements will be established to help guide the studies, conceptual and detailed designs, development, test, and eventually deployment, operation and disposal activities associated with space nuclear propulsion. Strategic plans for quality assurance and reliability will be developed and implemented. Environmental impact assessments will be made for all activities to be conducted under the program potentially affecting the environment, including fabrication, testing, ground transportation, pre-launch, launch, operation, abort and disposal. Formal environmental impact statements will be developed for each activity.

\section{PROGRAMMATIC CHARACTERISTICS}

A vital NEP technology program has programmatic characteristics as well as technical.

It is an evolutionary program. Its ultimate focus is to provide NEP technology for an advanced propulsion system for piloted missions to Mars, but it has interim milestones to verify the technologies needed for interplanetary and SEI cargo missions. such interim milestones have been included in the technology plan and have been described in the previous section.

It is characterized by very close interagency cooperation between NASA, the Department of Energy (DOE), and the Department of Defense (DOD). Each of these agencies has interest in Nuclear Electric Propulsion for space propulsion applications, either from the standpoint of being the ultimate user or of being a key resource in its technological development. DOE brings to bear far more than just expertise in nuclear energy (reactors), but 
aloo expertise (and facilities) for electric thrusters, advanced power conversion, thermal management, and instrumentation and control. A vital interagency program in NEP technology closely involves the non-nuclear expertise resident within DOE as well as NASA.

It is characterized by strong interagency support for project milestones. Those milestones include:

1) Completion of NEP systems/ subsystems trade study by FY93.

2) Assessment of MW-class electric thruster performance limits by 1995 .

3) Verification of component life for kW-class electric thruster by 1998 .

4) Demonstration of light-weight, MW-class space power conversion in a relevant environment by 2000 .

5) Demonstration of $\mathrm{MMW}$-class space reactor in a relevant environment by 2005 .

It is carried on in parallel with the timely demonstration of sp100 space reactor and power conversion technologies. Completion of final ground system testing of SP-100 by 1998 (in concert with component life verification of a $\mathrm{kW}$-class electric thruster) would esentially provide ground verification of the NEP technologies required for near-Earth and interplanetary robotic missions of the first decade of the 2000's. The timely completion of the SP-100 technology program, may very well allow a near term flight demonstration of a space nuclear system.

\section{SUMMARY}

An overview has been given of the plans for a program in Nuclear Electric Propulsion (NEP) Technology, and programmatic characteristics have been stated. NEP offers promise to a range of space propulsion applications from Earth-space to Mars piloted missions. Both the ultimate goals and interim milestones in this technology program have promise to provide the necessary technology to enhance or enable this range of missions.

\section{ACKNOWLEDGEMENT}

The author wishes to wholeheartedly acknowledge the support and participation of the members of the NEP Technology panel in this paper. This group of people gladly participated on their own volition (and their agency's own travel budget) in an eight month 
panel process, providing the technical content of the technology plans. This paper is a tribute to them and is a public opportunity to thank them for their support.

\section{REFERENCES}

1. J.S. Clark and T.J. Miller, "Nuclear Rocket Propulsion, NASA Plans and Progress-FY 1991," NASA Technical Memorandum 104455, Aug., 1991

2. "America at the Threshold - America's Space Exploration Initiative", Report of the Synthesis Group, available from the Superintendent of Documents, U.S. Government Printing Office, Washington, D.C. 20402, June, 1991

3. G.I. Bennett, S.R. Graham, K.F. Harer, "Back to the Future: Using Nuclear Propulsion to Go to Mars", AIAA 91-1888,

AIAA/SAE/ASME 27th Joint Propulsion Conference, Jun., 1991

4. R.P. Nagorski and R.J. Boain, "An Evaluation of Nuclear Electric Propulsion for Planetary Exploration Missions," AIAA 810705, Apr., 1981

5. D.I. Devincenzi, et al, "Elite systems Analysis," AIAA 902530, Jul.,1990

6. K.J. Hack, J.A. George and I.A. Dudzinski, "Nuclear Electric Propulsion Mission Performance for NASA Missions, AIAA 91-3488, Sep., 1991

7. c.w. Yen, "Nuclear Electric Propulsion for Future NASA Space Science Missions," IEPC 91-035, AIDAA/AIAA/DGLR/JSASS 22nd International Electric Propulsion Conference, Oct.,1991

8. J.W. Barnett, "Nuclear Electric Propulsion Technologies: Overview of the NASA/DOE/DOD Nuclear Electric Propulsion Workshop," Proceedings of the Eighth Symposium on Space Nuclear Power Systems, CONF-910116, Jan.,1991

9. J.A. George, "Multimegawatt Nuclear Power Systems for Nuclear Electric Propulsion," AIAA 91-3607, Sep.,1991

10. R.J. Hack, J.A. George and J.P. Riehl, "Evolutionary Use of Nuclear Electric Propulsion," AIAA 90-3821, Sept.,1990

11. S. Bhattacharyya, "Development of Nuclear Fuels and Materials for Propulsion Systems for SEI," AIAA 91-3452, Sep., 1991 
12. J.E. Dudenhoefer and J.M. Winter, "Status of NASA's Stirling Space Power Converter Program," Proceedings of the 26 th Intersociety Energy Conversion Engineering Conference, Aug.,1991

13. R. Holcomb, "Status of Rankine-Cycle Technology for Space Nuclear Power Applications," AIAA 91-3609, Sep.,1991

14. J. Martinell and J. Warren, "NASA/DOE/DOD Nuclear Rocket Propulsion Major Facility Reguirements," AIAA 91-3414, Sep.,1991

15. A. Marshall, "A Recommended Interagency Nuclear Propulsion Safety Policy," AIAA 91-3630, Sep.,1991

\section{NEP SUBSYSTEM TECHNOLOGY OPTIONS}

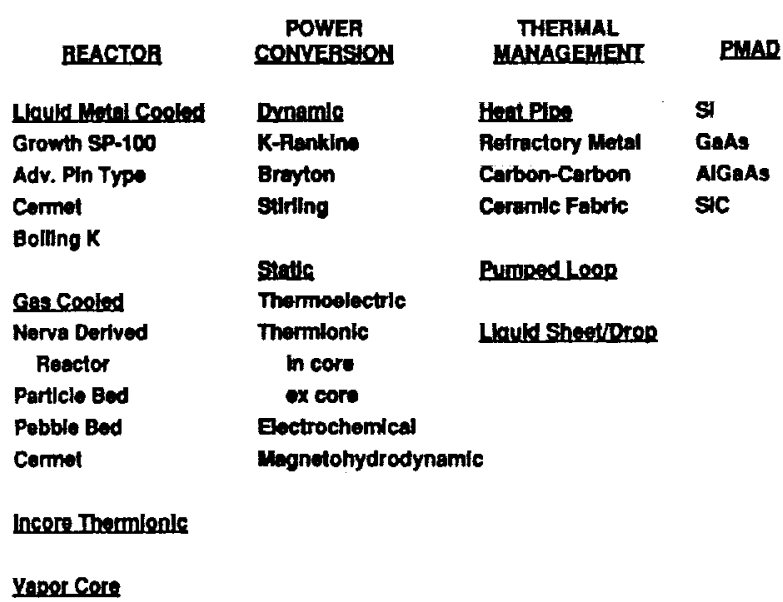

Table 1

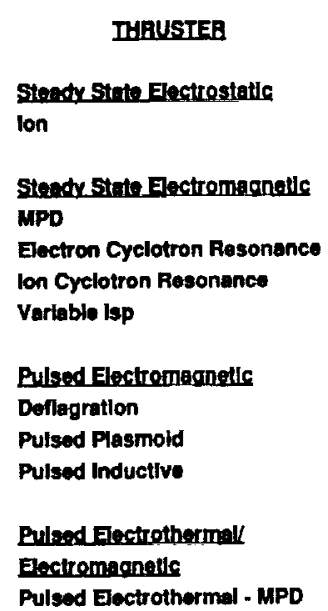

Pulsed Eectrothermal - MPD

\section{NEP TECHNOLOGY PANEL}

OBJECTIVE: $\quad$ To characterize NEP system options, including integrated reactor/thruster considerations, using common ground rules and assumptions. To initiate planning for a NEP technology program.

PRODUCTS: - Methodology for evaluating candidate power/propulsion systems

- Identification of nuclear and non-nuclear technology needs/plan

- Definition of facility requirements for NEP

- Requirements for NEP Systems Trade Study

- Final Report

Figure 1 


\section{NEP MISSION GUIDELINES}

\begin{tabular}{|c|c|c|c|c|c|c|c|c|}
\hline Mission & $\begin{array}{l}\text { Total } \\
\text { Power } \\
\text { (MWe) }\end{array}$ & $\begin{array}{l}\text { Thruster } \\
\text { Power } \\
\text { (MWe) }\end{array}$ & $\begin{array}{c}\text { Operating } \\
\text { Time } \\
\text { (v) }\end{array}$ & $\begin{array}{l}\text { Thruster } \\
\text { Time } \\
\text { (y) }\end{array}$ & $\begin{array}{l}\text { Isp } \\
\text { (s) }\end{array}$ & $\begin{array}{l}n \\
(\%)\end{array}$ & $\begin{array}{l}\text { Specific } \\
\text { Mass }(\alpha) \\
\text { (kg/kWe) }\end{array}$ & $\begin{array}{l}\text { Need } \\
\text { Date }\end{array}$ \\
\hline $\begin{array}{l}\text { Orbital Transfer/ } \\
\text { Precursor }\end{array}$ & $0.1-1$ & $0.01 \cdot 0.05$ & $3-10$ & $1 \cdot 2$ & $\begin{array}{r}2000 \\
-8000\end{array}$ & $>50$ & $10 \cdot 30$ & 2000 \\
\hline $\begin{array}{l}\text { Interplanetary } \\
\text { Probe }\end{array}$ & $0.1-1$ & $0.01=0.05$ & $10-12$ & $6 \cdot 10$ & $\begin{array}{l}5000 \\
-10000\end{array}$ & $>50$ & $30-50$ & 2000- \\
\hline Lunar Cargo & $0.5 \cdot 5$ & $0.1-1$ & $3-10$ & $1 \cdot 2$ & $\begin{array}{l}3000 \\
-10000\end{array}$ & $>50$ & $10-20$ & 2008- \\
\hline Mars Cargo & $2-10$ & $0.5 \cdot 2$ & $2 \cdot 10$ & $2 \cdot 3$ & $\begin{array}{l}5000 \\
-10000\end{array}$ & $>50$ & $10-20$ & 2010 \\
\hline Mars Piloted & $5 \cdot-40^{*}$ & $1 \cdot 5$ & $2 \cdot 10$ & $1 \cdot 2$ & $\begin{array}{l}5000 \\
-10000\end{array}$ & $>50$ & $<10$ & 2014- \\
\hline
\end{tabular}

*Total Power Includes Option for Multiple Propulsion Modules

Figure 2

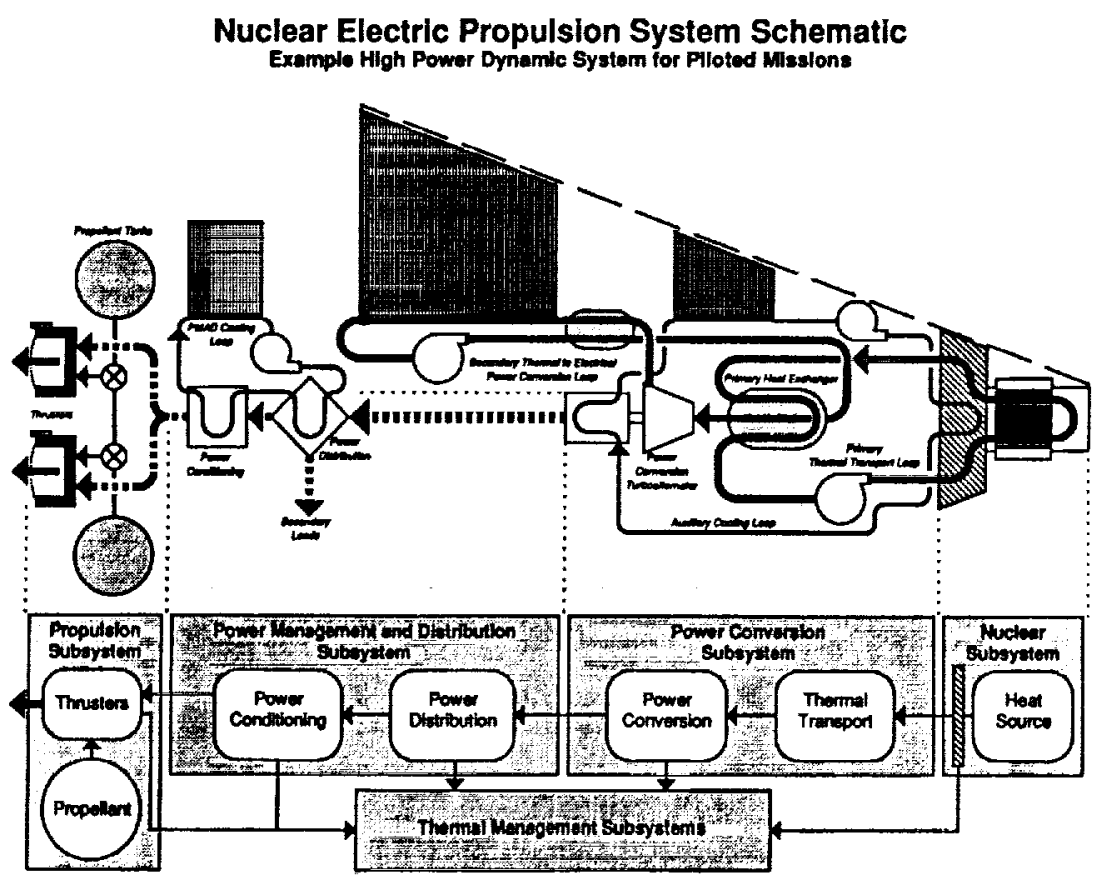

Figure 3 
NEP PROJECT PLAN OVERVIEW

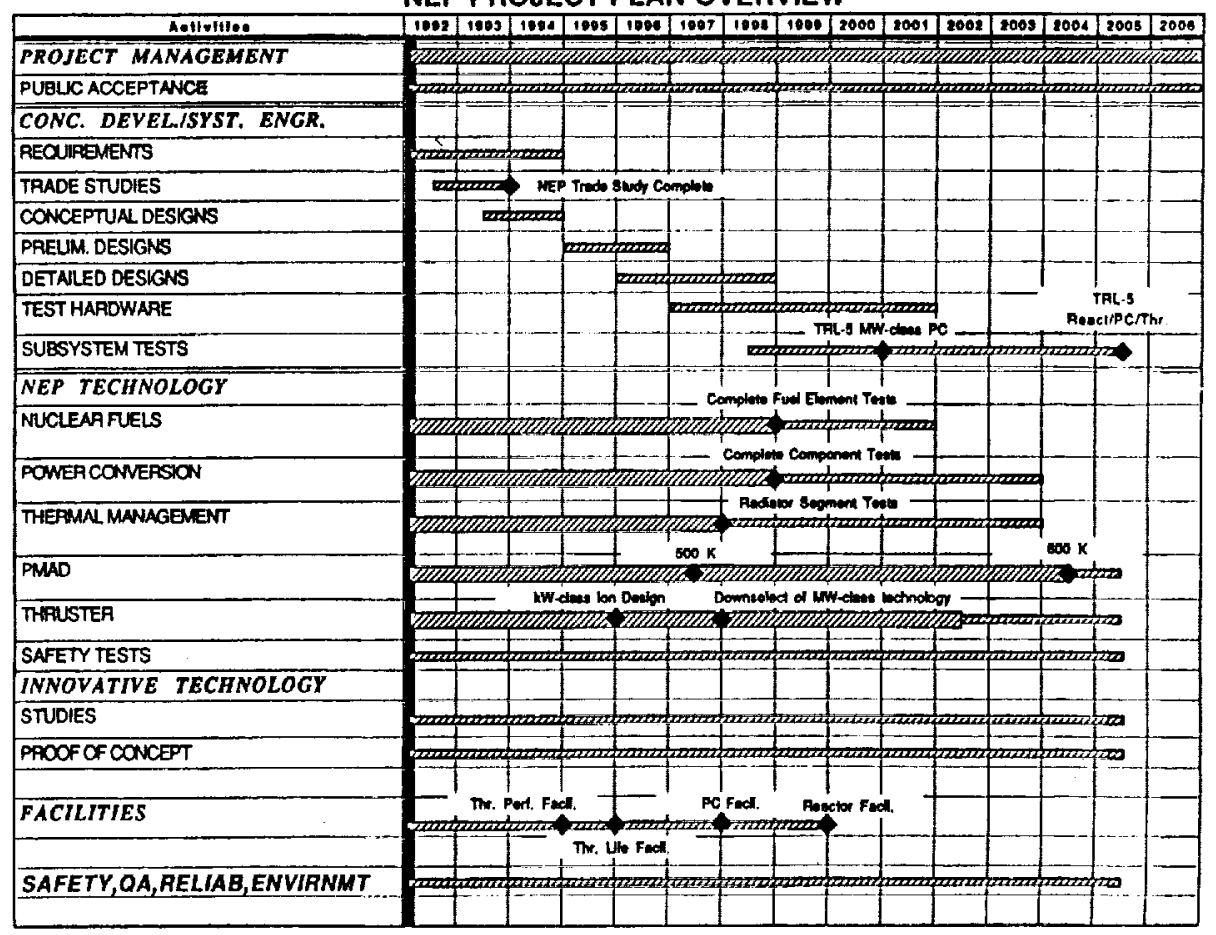

Flgure 4

\section{NEP Evolutionary Fuels Strategy}

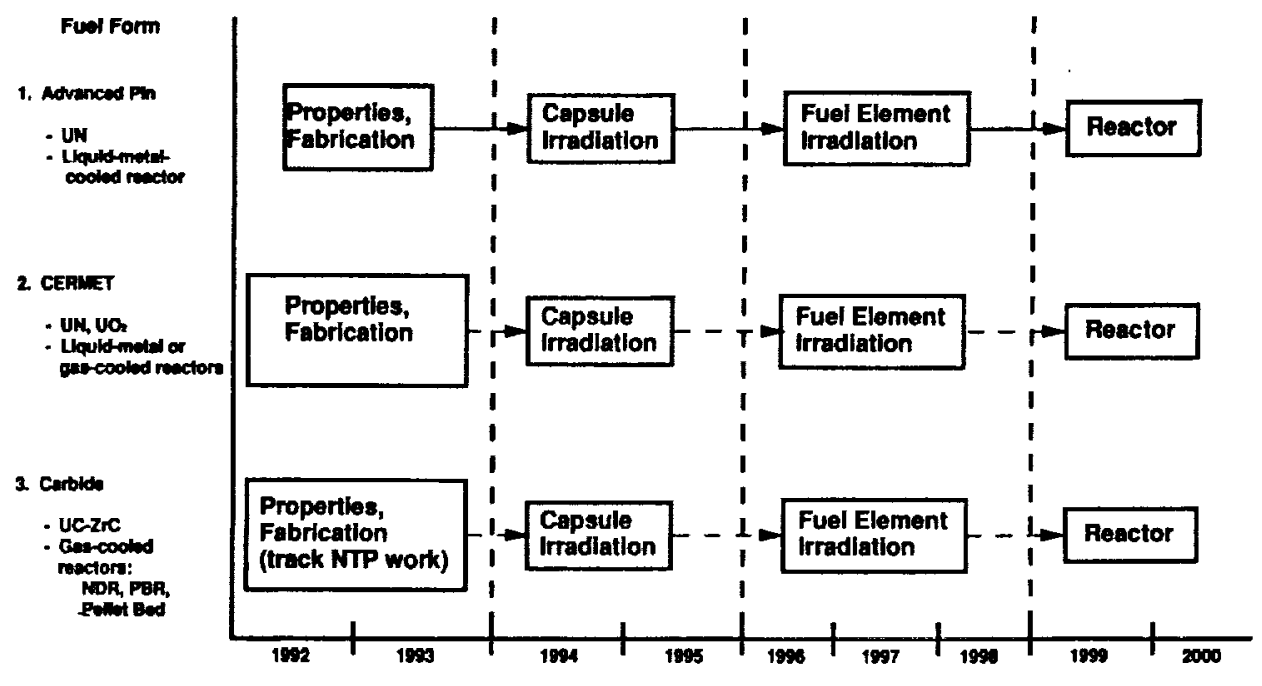

Fgure 5 
OVERVIEW OF

NEP ELECTRIC THRUSTER

COMPONENT TECHNOLOGY PLAN

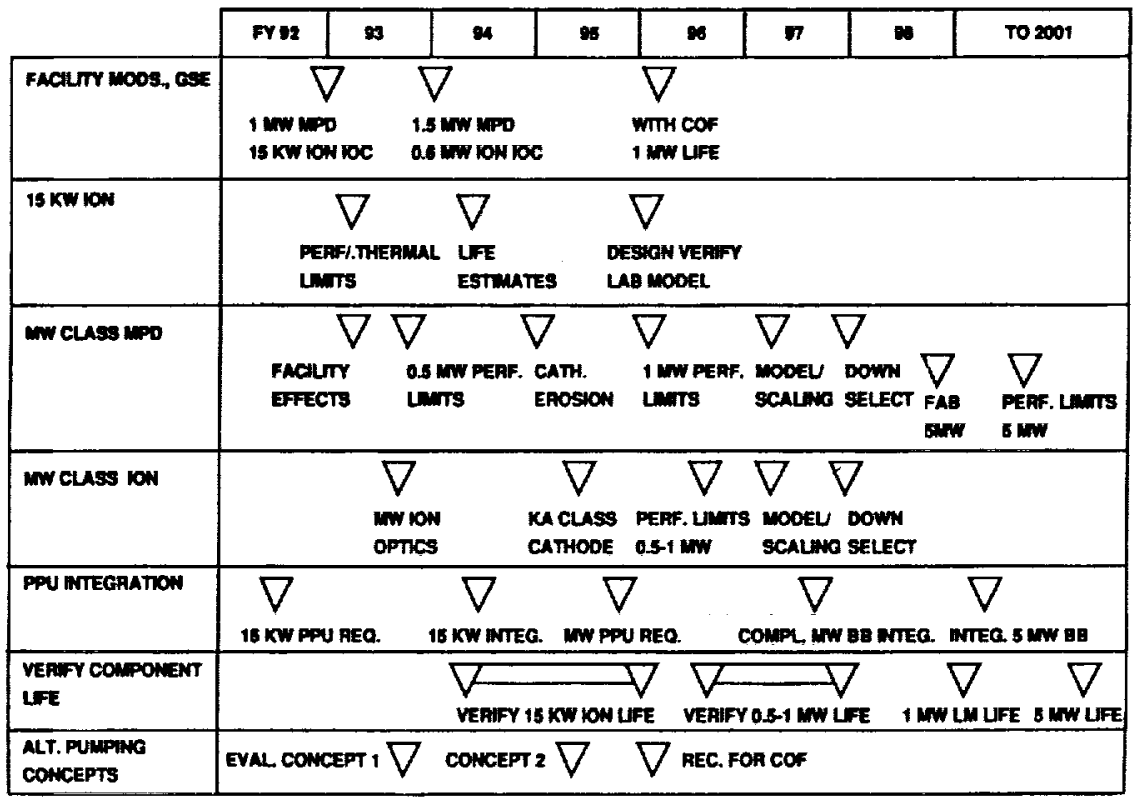

Figure 6 
4. TITLE AND SUBTITLE

5. FUNDING NUMBERS

Blazing the Trailway: Nuclear Electric Propulsion and its Technology

Program Plans

6. AUTHOR(S)

WU-593-72

Michael P. Doherty

\section{PERFORMING ORGANIZATION NAME(S) AND ADDRESS(ES)}

8. PERFORMING ORGANIZATION REPORT NUMBER

National Aeronautics and Space Administration

Lewis Research Center

Cleveland, Ohio 44135-3191

E-6941

9. SPONSORING/MONITORING AGENCY NAMES(S) AND ADDRESS(ES)

10. SPONSORING/MONITORING AGENCY REPORT NUMBER

National Aeronautics and Space Administration

Washington, D.C. 20546-0001
NASA TM-105605

AIAA-91-3441

\section{SUPPLEMENTARY NOTES}

Prepared for the Conference on Advanced Space Exploration Initiative Technologies cosponsored by AIAA, NASA, and OAI, Cleveland, Ohio, September 4-6, 1991. Responsible person, Michael P. Doherty, (216) 977--7092.

Unclassified - Unlimited

Subject Category 20

\section{ABSTRACT (Maximum 200 words)}

This paper gives an overview of the Nuclear Electric Propulsion (NEP) technology program plans, and states characteristics of a program in NEP technology to identify and develop enabling technologies to take humans further into outer space than we have cver gone before, and to allow us greater flexibility to perform our required activity at destination. NEP offers great promise for enhancing or even enabling both piloted and unpiloted missions to the Moon and Mars, robotic science missions to the outer reaches of our solar system and beyond, and Earth-space propulsion missions. NEP Technology Program plans are driven by the need to develop the propulsion technologies required for piloted and cargo missions to the Moon and Mars, as will be required for the U.S. Space Exploration Initiative. But because interim technology developments can yield NEP technologies for robotic science and Earthspace applications, an evolutionary technology program with carefully planned programmatic milestones is being formulated. Such an evolutionary approach to the development of NEP technology may very well allow a NEP propelled vehicle to serve as a national space nuclear power/propulsion pathfinder, thus blazing the trailway to other advanced space nuclear missions.

\begin{tabular}{|c|c|c|}
\hline \multicolumn{3}{|l|}{$\begin{array}{l}\text { 14. SUBJECT TERMS } \\
\text { Nuclear: Propulsion (adva }\end{array}$} \\
\hline $\begin{array}{l}\text { 17. SECURITY CLASSIFICATION } \\
\text { OF REPORT } \\
\text { Unclassified }\end{array}$ & $\begin{array}{l}\text { 18. SECURITY CLASSIFICATION } \\
\text { OF THIS PAGE } \\
\text { Unclassified }\end{array}$ & $\begin{array}{l}\text { 19. SECURITY CLASSIFICATION } \\
\text { OF ABSTRACT } \\
\text { Unclassified }\end{array}$ \\
\hline
\end{tabular}

